\title{
Freeze drying of natural deep eutectic solvent (NADES) extract of green coffee bean (Coffea canephora Pierre ex A. Froehner)
}

\author{
Rensa Alsya FITRI 1 (D), Tia Andriani LESTARI $1{ }^{1}$, , Yunita SARI ${ }^{1}$ (D), Sutriyo SUTRIYO ${ }^{2}$ (D), \\ Abdul MUN'IM 1,3* \\ 1 Department of Pharmacognosy-Phytochemistry, Faculty of Pharmacy, Universitas Indonesia, 16424, Depok, \\ Indonesia. \\ 2 Department of Pharmaceutical Technology, Faculty of Pharmacy, Universitas Indonesia, 16424, Depok, Indonesia. \\ 3 Graduate Program of Herbal Medicine, Faculty of Pharmacy, Universitas Indonesia, 16424, Depok, Indonesia. \\ * Corresponding Author. E-mail: munim@farmasi.ui.ac.id (A.M.); Tel. +62-21-788 49001.
}

Received: 31 October 2019 / Revised: 05 February 2020/ Accepted: 16 February 2020

\begin{abstract}
Natural Deep Eutectic Solvent (NADES) as green solvent had succeeded in attracting caffeine and chlorogenic acid from green coffee beans. NADES has very low eutectic points and chlorogenic acid in extract is thermolabile so that freeze-drying is suitable as drying method. This study aimed to produce and investigate the effect of addition of maltodextrin, Arabic gum and Aerosil ${ }^{\circledR}$ in freeze-dried NADES extract of green coffee beans and obtain the validation method of NADES extract by HPLC. In pretreatment of freeze drying, addition of water was needed as antisolvent and excipients (maltodextrin, Arabic gum, and its combination at $25 \%, 30 \%$, and $35 \%$ and Aerosil ${ }^{\circledR}$ at $1 \%$, $2 \%$, and $3 \%$ ) were added to improve the quality of dried extract. All samples were frozen first at $-80^{\circ} \mathrm{C}$ for 24 hours, then freeze drying was carried out for 26 hours under pressure conditions of 0.036 mbar and ice condenser temperature of $-104.7^{\circ} \mathrm{C}$. The freeze-dried products were evaluated for caffeine and chlorogenic acid content, yield drying, and moisture content. Caffeine and chlorogenic acid levels had a significant difference $(p<0.05)$ to the addition of different excipients. Moisture content had a significant effect on the addition of excipients and Aerosil ${ }^{\circledR}(p<0.05)$ while the drying yield had no significant effect $(p>0.05)$. The freeze-dried extract had been dried successfully that the increasing excipients improve the physical qualities and reducing stickiness.
\end{abstract}

KEYWORDS: Aerosille; arabic gum; freeze drying; green coffee bean; maltodextrin; NADES.

\section{INTRODUCTION}

Indonesia is the fourth largest coffee provider in the world after Brazil, Vietnam and Colombia. Coffee is known for its caffeine content, a derivative of xanthine alkaloids that has an antidepressant effect [1]. Some studies show that coffee has several health benefits, including antiobesity, antihyperglycemia and antihypertension [2]. The benefits are mostly obtained from green coffee beans (Coffea canephora Pierre ex A. Froehner) that do not go through the roasting process because they have a lot of polyphenol compounds which have antioxidant activity, one of which is chlorogenic acid (5-12 g / $100 \mathrm{~g})$ [3].

The use of Natural Deep Eutectic Solvent (NADES) as an environmentally friendly solvent has been widely applied for the extraction of secondary metabolites from plants [4]. Previous research conducted by Yuniarti et al. (2019) have succeeded in optimizing the extraction of chlorogenic acid and caffeine from green coffee beans (Coffea canephora Pierre ex A. Froehner) using NADES solvents consisting of choline chloride and sorbitol and extracted by the ultrasound assisted extraction (UAE) method [5].

The drying process in liquid extracts is carried out to obtain the minimum amount of moisture to ensure the stability of the content of polyphenol compounds [6]. There are several types of extract extraction drying method, one of which is freeze-drying. Freeze drying can be used for thermolabile compounds so that it can maintain stability when compared to oven-drying and spray-drying methods. Therefore, the freeze-drying method is suitable for drying extracts containing antioxidant compounds, such as chlorogenic acid which has thermolabile properties [7]. However, freeze-drying products can easily absorb moisture from the environment, resulting in adhesion, and the use of NADES as extraction solvents that have low eutectic points

How to cite this article: Fitri RA, Lestari TA, Sari Y, Sutriyo S, Mun'im A. Freeze drying of natural deep eutectic solvent (NADES) extract of green coffee bean (Coffea canephora Pierre ex A. Froehner). J Res Pharm. 2020; 24(2): 225-232. 
is a challenge in drying extracts because the presence of choline chloride as one of the NADES components is highly hygroscopic so that it can attract external humidity. Therefore, excipients need to be added to prevent stickiness [8].

The most commonly used excipients are maltodextrin, arabic gum and its combinations. Maltodextrin has good solubility and low viscosity although in high concentrations, it functions as a filler in dry extract, generally being dried extract powder. Arabic gum has a higher glass transition temperature (Tg) and has the ability as an emulgator [9]. In addition, the addition of Aerosil ${ }^{\circledR}$ as an adsorbent in the results of freeze-drying is needed to improve drying quality because it has a fine powder form, high surface area and high adsorbent power [10].

Based on previous research, up to now the data related to drying of green coffee bean extracts using water solvents with percolation extraction method has been carried out by the method of freeze-drying and spray-drying [11]. Nortuy et al. (2018) has conducted a study on the use of maltodextrin and silicon dioxide as anticaking for the spray drying process of dates (Phoenix dactylifera L.) to produce better quality powder by reducing hygroscopicity and low moisture content [12]. However, until now there has been no research on the drying of green coffee bean extract (Coffea canephora) which uses NADES using the freeze drying method. Therefore, in this study the extraction of green coffee beans was carried out using choline chloride and sorbitolbased NADES using the UAE method (Ultrasound-assisted Extraction) and drying extract using freeze drying method. The excipients used were maltodextrin, arabic gum and a combination of maltodextrin and arabic gum, and the addition of Aerosil ${ }^{\circledR}$ as an adsorbent.

\section{RESULTS AND DISCUSSION}

\subsection{Extraction process}

Extraction of green coffee beans with NADES solvents in the UAE method provides optimal results for attracting secondary metabolites of caffeine and chlorogenic acid. This can be influenced by the composition of the NADES solvent, addition of water, extraction time, method and extraction conditions used. NADES solvents were made by heating and stirring in a mixture of compounds choline chloride and sorbitol (4:1) will decrease the melting point lower than each component until it reaches the eutectic point so that it becomes a liquid at room temperature. This happens because NADES is able to receive and donate protons and electrons to form hydrogen bonds that were responsible for decreasing the mixed melting point [13]. The addition of water at NADES was carried out to reduce viscosity based on a study conducted by Mulia et al. (2015), high viscosity in NADES is difficult to break the intermolecular bonds to form new bonds with metabolites [14]. Therefore, the low solvent viscosity has a higher diffusion coefficient so that it can increase the extraction rate. The UAE method was short time efficiency, less amount of solvent used, increased sample surface area, cheap, easy to use, environmentally friendly and available in the laboratory. Ultrasonic waves cause damage to plant cell walls which results in the release of cell content into the extraction medium [15].

\subsection{Determination of caffeine and chlorogenic acid level in NADES extract by HPLC}

Analysis of compounds in liquid extract samples can be determined by comparing the chromatogram profile of the sample and the standard of caffeine and chlorogenic acid. The retention time of caffeine and chlorogenic acid obtained in the sample were the same as the standard at about 8.5 and 11 minutes, respectively (Figure 1).

The caffeine and chlorogenic acid levels obtained in the extract of NADES green coffee beans were 18.70 $\mathrm{mg} / \mathrm{g}$ and $42.63 \mathrm{mg} / \mathrm{g}$ of green coffee powder, respectively. The value of the obtained levels were quite large when compared with previous studies by Yuniarti et al. (2019), $4.49 \mathrm{mg} / \mathrm{g}$ and $16.59 \mathrm{mg} / \mathrm{g}$ of green coffee powder, respectively [5].

\subsection{Method validation}

The linear regression equation and regression coefficients $(\mathrm{r})$ of the calibration curves for caffeine and chlorogenic acid were $y=52.705 x+77.856, r=0.9996$ and $y=27.722 x-31.202, r=0.9996$, respectively. This shows that the $r$ value of more than 0.999 states that there is a relationship between concentration $(x)$ and response (y) which is interpreted as linearity.

LOD (Limit of Detection) is the concentration of the lowest analyte in a sample that can still be detected, although it cannot always be quantified. LOQ (Limit of Quantitation) is the lowest concentration of analytes in a sample that can be determined with acceptable precision and accuracy in the operational conditions used 
[16]. The LOD obtained based on the results of the calibration curve were 1.58 and $1.85 \mu \mathrm{g} / \mathrm{ml}$ respectively for caffeine and chlorogenic acid, and LOQ was 5.26 and $6.17 \mu \mathrm{g} / \mathrm{ml}$, respectively (Table 1).
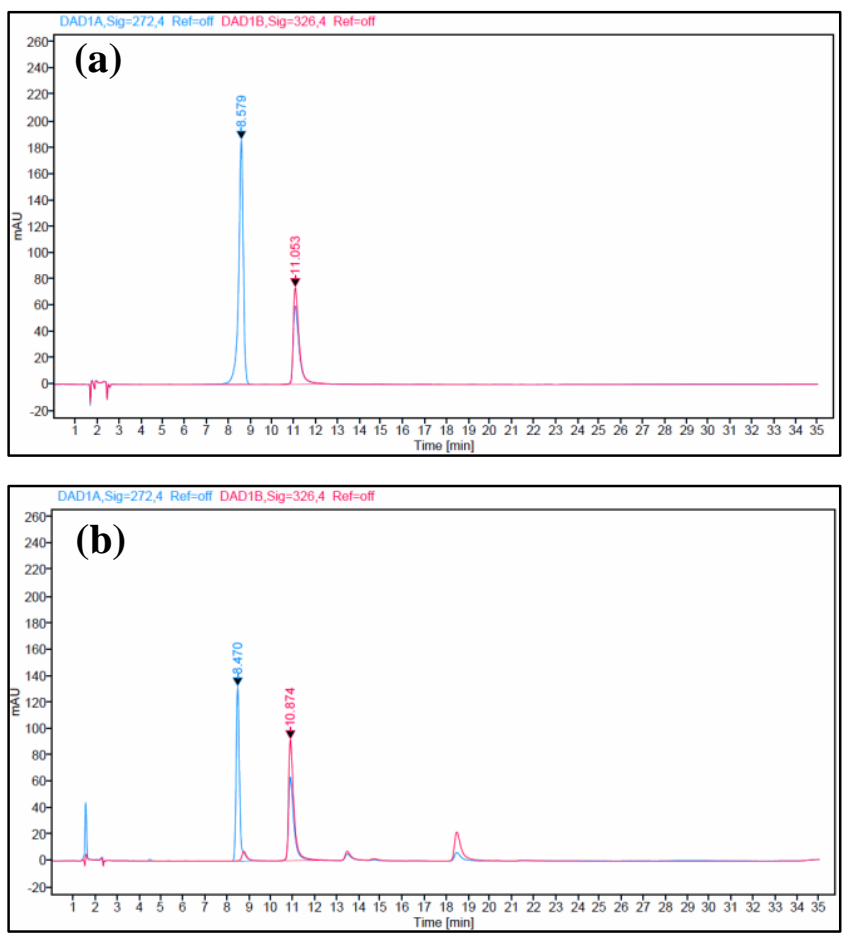

Figure 1. HPLC chromatograms of caffeine and chlorogenic acid in the standard (a) and sample test (b) solutions at $272 \mathrm{~nm}$ and $326 \mathrm{~nm}$.

Table 1. The LOD and LOQ result of caffeine and CGA.

\begin{tabular}{ccc}
\hline Analyte & LOD $(\mu \mathrm{g} / \mathrm{g})$ & LOQ $(\mu \mathrm{g} / \mathrm{g})$ \\
\hline Caffeine & 1.58 & 5.26 \\
CGA & 1.85 & 6.17 \\
\hline
\end{tabular}

Precision result on intraday and interday in this method was acceptable for caffeine with yield of RSD was lower than $0.67 \mathrm{CV}$ Horwitz so that it shows good precision requirements, but unacceptable for chlorogenic acid (Table 2). Accuracy of caffeine shows the yield of recovery in the range at $90-110 \%$, and recovery of chlorogenic acid is not acceptable with under $90 \%$ (Table 3).

Table 2. The precision yield of caffeine and CGA $(n=6)$.

\begin{tabular}{ccccc}
\hline \multirow{2}{*}{ Analyte } & \multicolumn{2}{c}{ Intra-day } & \multicolumn{2}{c}{ Inter-day } \\
\cline { 2 - 5 } & RSD & $\mathbf{0 . 6 7}$ CV Horwitz (\%) & RSD & $\mathbf{0 . 6 7}$ CV Horwitz (\%) \\
\hline Caffeine & 6.51 & 7.19 & 7.05 & 7.35 \\
\hline CGA & 6.97 & 5.98 & 13.51 & 6.05 \\
\hline
\end{tabular}

Table 3. The recovery yield of caffeine and CGA $(n=6)$.

\begin{tabular}{cccccc}
\hline Analyte & $\begin{array}{c}\text { Analyte } \\
(\mu \mathrm{g} / \mathbf{m l})\end{array}$ & $\begin{array}{c}\text { Amount of spike } \\
(\boldsymbol{\mu} \mathbf{g} / \mathbf{m l})\end{array}$ & $\begin{array}{c}\text { Total Analyte } \\
(\boldsymbol{\mu g} / \mathbf{m l})\end{array}$ & $\begin{array}{c}\text { Recovery }(\%) \\
( \pm \mathbf{S D})\end{array}$ & RSD \\
\hline Caffeine & 13.68 & 9.86 & 23.48 & $99.27 \pm 6.50$ & 6.55 \\
\hline CGA & 46.88 & 9.75 & 57.73 & $76.11 \pm 7.96$ & 10.46 \\
\hline
\end{tabular}

\subsection{Evaluation of freeze dried extract NADES of green coffee bean}

\subsubsection{Caffeine and chlorogenic acid content}

Retain levels of caffeine and chlorogenic acid based on Table 4 have significant differences in different excipients, especially arabic gum $(\mathrm{p}<0.05)$. These results are accordance with previous study by Ballesteros et 
al (2017), that the freeze-dried of spent coffee grounds with arabic gum had the lowest CGA concentration, compared with maltodextrin and the combination of maltodextrin and arabic gum [17]. This can be caused by the addition of arabic gum to the dried extract of green coffee beans can increase the viscosity of the sample solution before analysis, so that the increased concentration of arabic gum, the detected caffeine and chlorogenic acid levels were getting smaller. This was because in the process of filtering sample solutions with $0.45 \mu \mathrm{m}$ micropore, it is possible that there were residual caffeine and chlorogenic acid which still interacts with arabic gum and does not participate in filtering. This case was similar to the previous study, in the preparation of coffee syrup, the thicker of the syrup caused by the addition of Na-CMC, the chlorogenic acid levels detected in HPLC seemed to decrease [18].

Table 4. Excipient factor effect to caffeine retain, CGA retain, yield and moisture content in freeze dried extract.

\begin{tabular}{|c|c|c|c|c|}
\hline Excipient (\%) & $\begin{array}{l}\text { Caffeine retain } \\
(\%)\end{array}$ & CGA retain $(\%)$ & Yield (\%) & $\begin{array}{l}\text { Moisture content } \\
(\%)\end{array}$ \\
\hline MD 25\% & $94.18 \mathrm{ab} \pm 1.68$ & $94.24^{\mathrm{a}} \pm 2.59$ & $94.33 \mathrm{a} \pm 1,07$ & $3.48 \mathrm{a} \pm 0.59$ \\
\hline MD 30\% & $93.36 \mathrm{ab} \pm 2.74$ & $96.43^{\mathrm{a}} \pm 1.40$ & $92.93 \mathrm{a} \pm 0,85$ & $3.89 \mathrm{ab} \pm 0.66$ \\
\hline MD 35\% & $95.59 \mathrm{a} \pm 1.37$ & $93.54^{\mathrm{a}} \pm 1.07$ & $93.43^{a} \pm 0,20$ & $4.61^{b} \pm 1.23$ \\
\hline GA $25 \%$ & $94.98 \mathrm{ab} \pm 4.85$ & $84.15^{b} \pm 1.61$ & $93.37 \mathrm{a} \pm 0,88$ & $3.41 \mathrm{ab} \pm 0.49$ \\
\hline GA $30 \%$ & $94.02 \mathrm{ab} \pm 0.50$ & $81.62^{b} \pm 3.48$ & $92.85^{\mathrm{a}} \pm 0,94$ & $3.91 \mathrm{ab} \pm 0.52$ \\
\hline GA $35 \%$ & $89.04^{b} \pm 3.09$ & $71.68^{c} \pm 1.78$ & $92 \cdot 11^{a} \pm 0,63$ & $4.29 \mathrm{ab} \pm 0.34$ \\
\hline MD-GA25\% & $96.39 \mathrm{a} \pm 1.96$ & $97.68^{a} \pm 1.13$ & $95.50 \mathrm{a} \pm 0,73$ & $2.57 \mathrm{ab} \pm 0.91$ \\
\hline MD-GA30\% & $96.66^{a} \pm 5.56$ & $96.58^{a} \pm 2.46$ & $92.23^{a} \pm 3,86$ & $3.29^{b} \pm 0.98$ \\
\hline MD-GA35\% & $91.35 \mathrm{ab} \pm 2.66$ & $92.65 \mathrm{a} \pm 2.32$ & $92.31 \mathrm{a} \pm 3,08$ & $4.43^{\mathrm{ab}} \pm 0.59$ \\
\hline
\end{tabular}

MD: maltodextrin; GA: arabic gum.

a-c mean values with different lowercase superscript letters within each column denote significant differences $(p<0,05)$ and values are mean $\pm \mathrm{SD}$.

Therefore, a solution that can be used in subsequent research needs to add a little acid in the dissolution process containing polysaccharides, because in acidic conditions hydrolysis can occur in the glycoside bonds in the polysaccharide in arabic gum so that the solution viscosity decreases [19].

\subsubsection{Drying yield}

Drying yield of extract was obtained by calculating the total mass of freeze-dried extract and total solid mass contained in a vial [20]. In this study, total powder mass was calculated from the results of the vial difference before and after freeze-drying at room temperature. So there should be no loss of powder. But in this study, the drying yield was less than $100 \%$ which could be caused by the presence of liquid extract attached to the aluminum layer used to cover the vials during the freeze-drying process. The solution that can be used is a larger container is needed to prevent the process of losing mass [21]. Table 4 shows that drying yields do not have a significant difference ( $p>0.05)$.

\subsubsection{Moisture content}

After the freeze-drying process, dry extract samples need to be measured by moisture content using the loss on drying method. The conventional method commonly used is by oven for 3 hours with a temperature of $105^{\circ} \mathrm{C}$ to reach a fixed weight. In this study, the Moisture Analyzer was used, where the time used was more efficient because the samples would automatically be measured to a fixed weight.

Measurement of moisture content in dry extract obtained the opposite results from previous study by Nortuy et al (2018) that the increasing of Aerosil ${ }^{\circledR}$ in the formulation, the moisture content will decrease [12]. Whereas in this study, in Table 5, the increasing concentration of Aerosil ${ }^{\circledR}$ produces moisture content which also increases and significantly different $(\mathrm{p}<0.05)$. This is due to the decreasing concentration of Aerosil ${ }^{\circledR}$, the dried extract is more soggy, making it difficult to spread evenly on the pan container, therefore, the moisture content measurement for lyophilize samples is not commonly used by using moisture analyzer. 
Table 5. The effect of Aerosil ${ }^{\circledR}$ on caffeine, CGA, drying yield and moisture content on freeze dried extract.

\begin{tabular}{ccccc}
\hline Aerosi1 $^{\circledR}(\mathbf{( \% )}$ & Caffeine (\%) & CGA (\%) & Yield (\%) & Moisture content (\%) \\
\hline $1 \%$ & $92.95 \mathrm{a} \pm 2.69$ & $89.70 \mathrm{a} \pm 8.79$ & $92.27 \mathrm{a} \pm 2.30$ & $3.15^{\mathrm{b}} \pm 0.51$ \\
$2 \%$ & $92.97 \mathrm{a} \pm 3.29$ & $89.31 \mathrm{a} \pm 9.38$ & $93.23 \mathrm{a} \pm 1.46$ & $3.70 \mathrm{~b} \pm 0.35$ \\
$3 \%$ & $94.15 \mathrm{a} \pm 2.65$ & $90.52 \mathrm{a} \pm 8.77$ & $94.18 \mathrm{a} \pm 1.19$ & $4.44{ }^{\mathrm{a}} \pm 0.16$ \\
\hline
\end{tabular}

a-b mean values with different lowercase superscript letters within each column denote significant differences $(p<0.05)$ and values are mean $\pm \mathrm{SD}$

\subsection{Freeze drying of extract sample}

The results of freeze-dried extract of green coffee bean on the addition of arabic gum make the extract more soggy. This is contrary to previous studies that the use of arabic gum has a better reducing clotting properties compared to maltodextrin [22]. This is due to the high viscosity of the sample using arabic gum, where the decrease in temperature in the freezing process does not form perfect ice, so that there is still water remaining in the liquid phase, which will remain until the final freeze-drying process [23]. Water molecules held in dry extract can reduce the glass transition temperature $(\mathrm{Tg})$, so that the dried extract becomes melted [24]. Therefore, the percentage of arabic gum in the formulation needs to be re-optimized and the addition of other appropriate excipients to optimally dry the NADES extract of green coffee beans.

\section{CONCLUSION}

The drying process of NADES extract of green coffee beans that have low eutectic point was successfully done and the results showed that with increasing concentrations of excipients and Aerosil ${ }^{\circledR}$ producing better dry extracts. The results of the retain analysis showed that the use of arabic gum could increase viscosity, thus, affect the sample solubility and reduce caffeine and CGA levels, the drying yield was not affected ( $p>0.05)$ by the addition of excipients and Aerosil ${ }^{\circledR}$, but it affected the moisture content of the freeze dried extract $(\mathrm{p}<0.05)$.

\section{MATERIALS AND METHODS}

\subsection{Plant materials and reagents}

Green coffee beans (Coffea canephora) were obtained from Sidikalang, North Sumatra collected on December 2018. The samples that had been designated by Center for Plant Conservation Botanic Gardens Indonesian Institute of Sciences with number letter 222/IPH.1.01/If.07/II/2019 were grounded and filtered. Caffeine standard (Jilin Shulan Synthetic Pharmaceutical, China), chlorogenic acid standard (Wako Pure Chemical Industries, Japan), Choline chloride (Rongsheng-Biotechnology, Co., Ltd., China), D-Sorbitol (Roquette Freres, France), acetonitrile HPLC grade (Merck), methanol HPLC grade (Merck), acetic acid (Merck), maltodextrin (PT. Bratacho, Indonesia), arabic gum (PT. Bratacho, Indonesia), Aerosil ${ }^{\circledR}$ (PT. Bratacho, Indonesia), Aqua Pro-Injection (PT. Ikapharmindo Putramas, Indonesia), aquadest (PT. Ikapharmindo Putramas, Indonesia), ethanol (PT. Bratacho, Indonesia).

\subsection{Instrumentation}

Ultrasonic (Krisbow, China), micropippette (Thermo Scientific, USA), High Performance Liquid Chromatography (Agilent 1200 series HPLC, USA), HPLC column Inertsil Octadecyisilane (ODS)-3 $5 \mu \mathrm{m}$ (4.6 x 150 mm C18, GL Sciences, Tokyo, Japan), moisture analyzer (HE73 Mettler Toledo), centrifuge (HeraeusChrist GmbH, Osterode, Germany), hotplate stirrer (IKA ${ }^{\circledR}$ C-MAG HS 4, Germany).

\subsection{Preparation of natural deep eutectic solvent (NADES)}

NADES was prepared from a mixture of choline chloride (hydrogen bond acceptor) and sorbitol (hydrogen bond donor) components with a mol ratio of 4:1. The mixture was heated and stirred using a hotplate stirrer at $80^{\circ} \mathrm{C}$ until clear and homogenous liquid is formed and then diluted with $50 \% \mathrm{v} / \mathrm{v}$ water [5].

\subsection{Extraction process}

Extraction of green coffee with a ratio of coffee powder and NADES solvent 1:30 and then sonicated for 60 minutes. NADES liquid extract was centrifuged at $4500 \mathrm{rpm}$ for 17 minutes [5]. Liquid extract was diluted with water to analyze caffeine and chlorogenic acid using HPLC. 


\subsection{Freeze drying sample preparation}

The NADES liquid extract of green coffee beans that have been prepared was formulated using maltodextrin excipients (DE 10-15), arabic gum and a combination of maltodextrin and arabic gum (1: 1) at 25; $30 ; 35 \%(\mathrm{w} / \mathrm{v})$, and Aerosil ${ }^{\circledR}$ at $1 ; 2 ; 3 \%(\mathrm{w} / \mathrm{v})$, respectively. Preparation was carried out with a slight modification of Tolun et al. (2016) and Suravanichnirachorn et al. (2018). Each excipient was dissolved in water, then NADES extract of green coffee beans (1:1) is added to each excipient solution. Water was added to the mixture in a ratio of $1: 3$. The mixture was then put into each vial of $6 \mathrm{~mL}$, then added Aerosil ${ }^{\circledR}$ at $1 ; 2$; $3 \%(\mathrm{w} / \mathrm{v})$, respectively. Freeze drying process, all samples were frozen first at $-80^{\circ} \mathrm{C}$ for 24 hours, then freeze drying was carried out for 26 hours under pressure conditions of $0.036 \mathrm{mbar}$ and ice condenser temperature of $-104.7^{\circ} \mathrm{C}$. The results of the dried extract from freeze drying were stored in tightly closed containers and stored in containers containing silica gel.

\subsection{Analysis condition of high performance liquid chromatography (HPLC)}

Analysis of caffeine and chlorogenic acid were determined by injecting a standard volume of $20 \mu \mathrm{L}$, flow rate of $1.0 \mathrm{~mL} /$ minute, mobile phase mixture of $0.1 \%$ acetic acid (A) and acetonitrile (B) with a 20 minutes gradient of $90 \% \mathrm{~A}$ and $10 \% \mathrm{~B}$, then converted to 10 minutes isocratic $80 \% \mathrm{~A}$ and $20 \% \mathrm{~B}$, and returns to the initial condition of $90 \% \mathrm{~A}$ and $10 \% \mathrm{~B}$ for 5 minutes, the wavelengths are $272 \mathrm{~nm}$ for caffeine and $326 \mathrm{~nm}$ for chlorogenic acid [12].

\subsection{Validation method}

Before doing this experiment, validation should be carried out by determining the linearity, limit of detection (LOD), limit of quantification (LOQ), accuracy, and precision for analyzing caffeine and CGA. Linearity was obtained from calibration curve with a standard stock solution of $200 \mathrm{ppm}$ chlorogenic acid and caffeine $(0.2 \mathrm{mg} / \mathrm{ml})$ in $70 \%$ ethanol, diluted to produce concentrations of 10, 20, 30, 40, 50 and $60 \mathrm{ppm}$. For obtaining linear regression equation, area $(\mathrm{y})$ and the concentration of the standard solution $(\mathrm{x})$ were plotted to become the calibration curve. The LOD and LOQ of chlorogenic acid and caffeine were obtained from calibration curve. Spiking the sample with standard solutions was done for getting recovery. Spiked and unspiked sample were extracted using NADES and analyzed by HPLC. Precision was obtained by extracting six sample of green coffee powder using NADES and then analyzed with intra-day and inter-day variation for 2 days. The precision parameter calculated by RSD $\leq 0.67 \times \mathrm{CV}$ Horwitz.

\subsection{Caffeine and chlorogenic acid content determination}

The NADES liquid extract was analyzed for caffeine and chlorogenic acid levels with a slight modification of Yuniarti et al. (2019). A liquid extract of $0.40 \mathrm{~mL}$ was diluted with aqua pro injection up to 10 $\mathrm{mL}$. Analysis of the freeze dried extract was carried out by weighing the sample around $200 \mathrm{mg}$ and dissolved in aqua pro injection up to $5 \mathrm{~mL}$ and then filtered [20].

\subsection{Yield drying}

The drying yield was evaluated by determining recovery resulting from the total mass of the product after freeze drying with total solid mass when formulation preparation [20]. Drying yield can be calculated based on the calculation of equation 1 :

Yield $(\%)=($ Amount of freeze dried extract $(\mathrm{g}) /$ Total solid content $) \times 100$

[Eq. 1]

\subsection{Moisture content}

Moisture content is analyzed using the moisture analyzer. The sample was heated at $105^{\circ} \mathrm{C}$ for 30 minutes until the weight remained. All analyzes were carried out in duplicate.

\subsection{Data analysis}

Data analysis was performed by Kruskal Wallis nonparametric analysis to determine the significance difference $(p<0.05)$ between each excipient and Aerosil ${ }^{\circledR}$ to the retain of caffeine and chlorogenic acid levels, yield of drying and moisture content. All measurements were done in triplicate. 
Acknowledgements: This study was financially supported by Directorate of Research and Community Enggagement (DRPM), Universitas Indonesia, via Hibah PITTA B 2019

Author contributions: Concept - A.M., S.S., R.A.F., T.A.L., Y.S. ; Design - A.M., R.A.F., T.A.L., Y.S. ; Supervision A.M., S.S. ; Resources - A.M., R.A.F., T.A.L., Y.S. ; Materials - A.M., R.A.F., T.A.L., Y.S. ; Data Collection and/or Processing - S.S., R.A.F., T.A.L., Y.S.; Analysis and/or Interpretation - S.S., R.A.F., T.A.L., Y.S.; Literature Search R.A.F., T.A.L., YS.; Writing - A.M., R.A.F., T.A.L., Y.S..; Critical Reviews -A.M., S.S., R.A.F., T.A.L., Y.S.

Conflict of interest statement: The authors declared no conflict of interest.

\section{REFERENCES}

[1] Yenisetti, Muralidhara. Beneficial role of coffee and caffeine in neurodegenerative disease: a minireview. AIMS Public Health. 2016; 3(2): 407-422. [CrossRef]

[2] Revuelta-Iniesta R, Al-Dujaili EAS. Consumption of green coffee reduces blood pressure and body composition by influencing 11ß-HSD1 enzyme activity in healthy individuals: a pilot crossover study using green and black coffee. BioMed Res Int. 2014; 2014: 1-9. [CrossRef]

[3] Farah A, Donangelo CM. Phenolic compounds in coffee. Braz J Plant Physiol. 2006; 18(1): 23-36. [CrossRef]

[4] Kerton FM. Alternative solvent for green chemistry. Green Chem. 2009; 118-142. [CrossRef]

[5] Yuniarti E, Saputri FC, Mun'im A. Application of the natural deep eutectic solvent choline chloride-sorbitol to extract chlorogenic acid and caffeine from green coffee beans (Coffea canephora). J Appl Pharm Sci. 2019; 9(3): 82-90. [CrossRef]

[6] Gil M, Wianowska D. Chlorogenic acids-their properties, occurrence and analysis. Annales UMCS, Chemia. 2017; 72(1): 61-104.

[7] Ayelign A, Sabally K. Determination of chlorogenic acid (CGA) in coffee beans using HPLC. Am J Res Commun. 2013; 1(2): 78-91.

[8] Phisu, N. Spray drying technique of fruit juice powder: some factors influencing the properties of product. Faculty of Agricultural Product Innovation and Technology, Srinakharinwirot University, Sukhumvit 23, Bangkok, 10110, Thailand. Int Food Res J. 2012; 19(4): 1297-1306.

[9] Ahmed J, Glass Transition and Phase Transitions in Food and Biological Materials. John Wiley and Sons, West Sussex, England 2017.

[10] Silva M, Ranil R, Fonseka R. Luffa cylindrica (L.) M. Roemer (Sponge Gourd-Niyan wetakolu): An emerging high potential underutilized cucurbit. Trop Agric Res. 2012; 23(2): 186-191. [CrossRef]

[11] Liu RTS et al. Soluble instant coffee prepared from extract obtained from green coffee. United States Patent. 1999.

[12] Nortuy N, Suthapakti K, Utama-ang N. Effects of maltodextrin and silicon dioxide added as anticaking agents on the properties of instant date palm (Phoenix dactylifera L.) powder using spray drying. J Adv Agric Technol. 2018; 5(2): 86-92. [CrossRef]

[13] Paiva PCP, de Paiva HN, de Oliveira Filho PM, Lamounier JA, Ferreira RC, Zarzar PM. Development and validation of a social capital questionnaire for adolescent students (SCQ-AS). PLoS ONE. 2014; 9(8): 1-8. [CrossRef]

[14] Mulia K, Terahadi F, Krisanti E, Putri S. Selected natural deep eutectic solvents for the extraction of a-mangostin from mangosteen (Garcinia mangostana L.) Pericarp. Int J Technol. 2015; 6(7): 1211-1220. [CrossRef]

[15] Syakfanaya AM, Saputri FC, Mun'im A. Simultaneously extraction of caffeine and chlorogenic acid from Coffea canephora bean using natural deep eutectic solvent-based ultrasonic assisted extraction. Phcog J. 2019; 11(2): $267-271$. [CrossRef]

[16] Choi HJ, Park DH, Song SH, Yoon IS, Cho SS. Development and validation of a HPLC-UV method for extraction optimization and biological evaluation of hot-water and ethanolic extracts of Dendropanax morbifera leaves. Molecules. 2018; 23(3): 650. [CrossRef]

[17] Ballesteros LF, Ramirez MJ, Orrego CE, Teixeira JA, Mussatto SI. Encapsulation of antioxidant phenolic compounds extracted from spent coffee ground by freeze-drying and spray-drying using different coating materials. Food Chemistry. 2017; 237: 623-631. [CrossRef]

[18] Budiman A, Luthfi A, Muchtaridi M. The stability of chlorogenic acid in syrup of coffee arabica (Coffea arabica L.) extract with decaffeination process. Asian J Pharm Clin Res. 2017; 10(14): 1-4. [CrossRef]

[19] Kasaai MR, Arul J, Charlet G. Fragmentation of chitosan by acids. Sci World J. 2013; 2013: 1-11. [CrossRef] 
[20] Tolun A, Altintas Z, Artik N. Microencapsulation of grape polyphenols using maltodextrin and gum arabic as two alternative coating materials: development and characterization. J Biotechnol. 2016; 239: 23-33. [CrossRef]

[21] Khairnar S, Harwalkar M, Kini R, Salunkhe K, Chaudhari DR. A review on freeze drying process of pharmaceuticals. Int J Res Pharm. 2012; 4(1): 76-94.

[22] Suravanichnirachorn W, Haruthaithanasan V, Suwonsichon S, Sukatta U, Maneeboon T. Effect of carrier type and concentration on the properties, anthocyanins and antioxidant activity of freeze-dried mao [Antidesma bunius (L.) Spreng] powders. Agriculture and Natural Resources. 2018; 52(4): 354-360. [CrossRef]

[23] Aschenbrenner M, Kulozik U, Forst P. Freeze-drying of probiotics. Advances in Probiotic Technology. 2015; $213-241$. [CrossRef]

[24] Drake AC, Lee Y, Burgess, EM, Karlsson, JO, Eroglu A, Higgins AZ. Effect of water content on the glass transition temperature of mixtures of sugars, polymers, and penetrating cryoprotectants in physiological buffer. PLoS ONE. 2018; 13(1): 1-15. [CrossRef]

This is an open access article which is publicly available on our journal's website under Institutional Repository at http://dspace.marmara.edu.tr. 